Document downloaded from:

http://hdl.handle.net/10251/164216

This paper must be cited as:

Belda, R.; Palomar-Toledano, M.; Peris Serra, JL.; Vercher Martínez, A.; Giner Maravilla, E. (2020). Compression failure characterization of cancellous bone combining experimental testing, digital image correlation and finite element modeling. International Journal of Mechanical Sciences. 165:1-12. https://doi.org/10.1016/j.jjmecsci.2019.105213

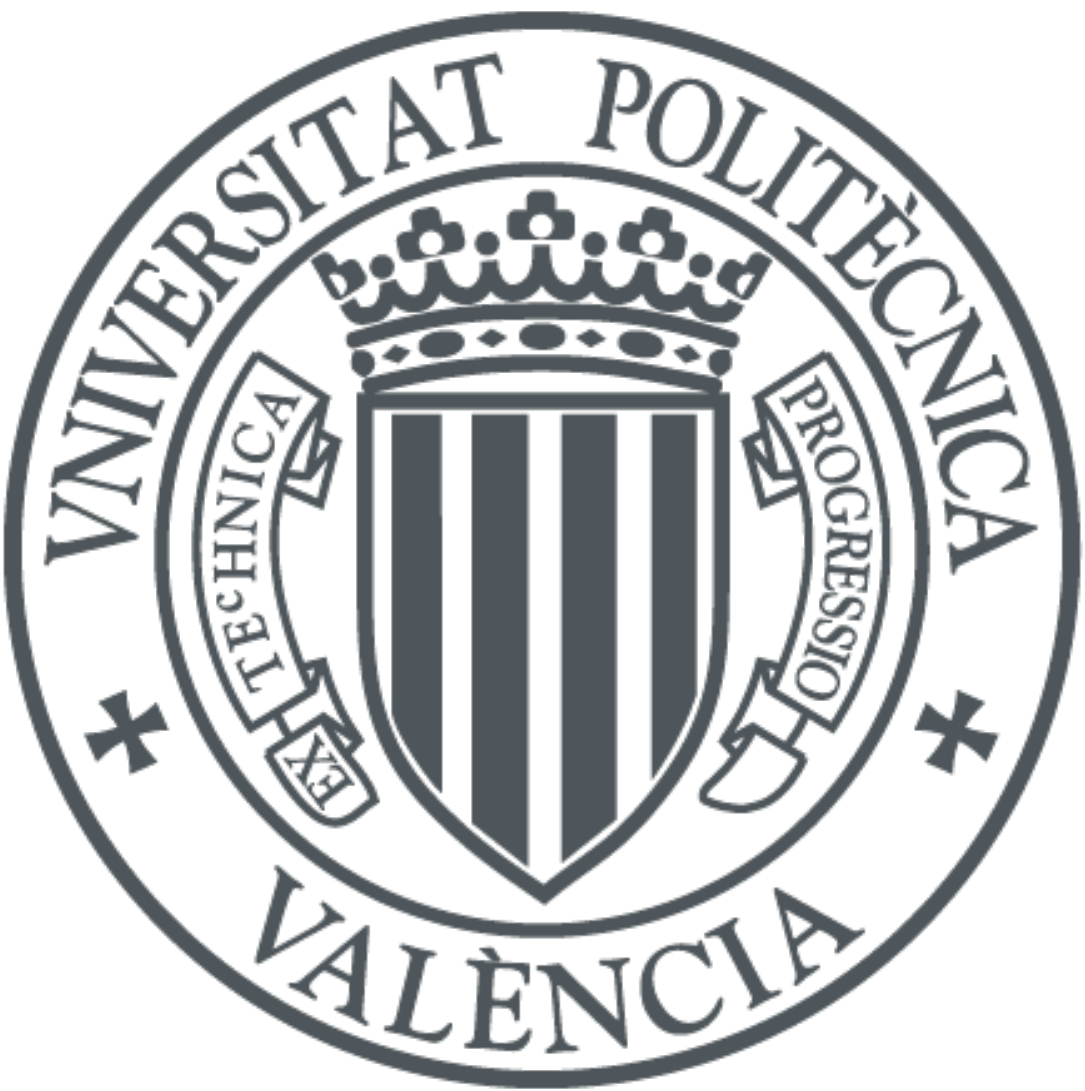

The final publication is available at

https://doi.org/10.1016/j.ijmecsci.2019.105213

Copyright Elsevier

Additional Information 


\title{
Compression failure characterization of cancellous bone combining experimental testing, digital image correlation and finite element modeling
}

\author{
Ricardo Belda ${ }^{\mathrm{a}, *}$, Marta Palomar ${ }^{\mathrm{a}}$, José Luis Peris-Serra ${ }^{\mathrm{b}, \mathrm{c}}$, \\ Ana Vercher-Martínez ${ }^{\mathrm{a}}$, Eugenio Giner ${ }^{\mathrm{a}}$ \\ ${ }^{a}$ Centre of Research in Mechanical Engineering - CIIM, Dept. of Mechanical Engineering \\ and Materials, Universitat Politècnica de València, Camino de Vera, 46022 Valencia, \\ Spain \\ ${ }^{b}$ Instituto de Biomecánica de Valencia (IBV), Universitat Politècnica de València, \\ Camino de Vera, 46022 Valencia, Spain \\ ${ }^{c}$ Healthcare Technology Group (GTS-IBV); Networking Biomedical Research Centre in \\ Bioengineering, Biomaterials and Nanomedicine (CIBER-BBN), Universitat Politècnica \\ de València, Building 9C, Camino de Vera s/n, 46022 Valencia, Spain
}

\begin{abstract}
Cancellous bone yield strain has been reported in the literature to be relatively constant and independent from microstructure and apparent density, while fracture strain shows higher scattering. The objective of this work is to assess this hypothesis, characterizing the compression fracture in cancellous bone from a numerical approach and relating it to morphological parameters. Quasi-static compression fractures of cancellous bone samples are modeled using high-resolution image-based finite elements, correlating the numerical models and experimental results. The yield strain and the strain at fracture are inferred from the micro-CT-based finite element models by inverse analysis. The validation of the fracture models is carried out
\end{abstract}

\footnotetext{
*Corresponding author. Tel.: +34-618243486.

Email address: ribelgon@upv.es (Ricardo Belda)
} 
through digital image correlation (DIC). To develop this work, cancellous bone parallelepiped-shaped specimens were prepared and micro-CT scanned at $22 \mu \mathrm{m}$ spatial resolution. A morphometric analysis was carried out for each specimen in order to characterize its microstructure. Quasi-static compression tests were conducted, recording the force-displacement response and a sequence of images during testing for the application of the DIC technique. This was applied without the need of a speckle pattern benefiting from the irregular microstructure of cancellous bone. The finite element models are also used to simulate the local fracture of trabeculae at the micro level using a combination of continuum damage mechanics and the element deletion technique. Equivalent strain, computed both from DIC and micro-FE, was the best predictor of the compression fracture pattern. The procedure followed in this work permits the estimation of failure parameters that are difficult to measure experimentally, which can be used in numerical models.

Keywords: Compression fracture characterization, cancellous bone, digital image correlation, micro-FE 


\section{Introduction}

Prediction of bone tissue failure has clinical relevance due to the major economic and social importance of bone injuries as our society has an increasing percentage of aged population [1]. At the macroscale, bone is composed of cortical and cancellous tissues. Cancellous bone is the primary location for orthopedic implant insertion, and it is claimed that has great

importance on macroscopic bone fracture [2]. The study of cancellous bone mechanical properties and therefore the determination of failure properties has clinical and research interest to improve fracture risk assessment. The hierarchical structure of bone makes it necessary to study its different scales to get insight about the mechanical behavior at each one and how it affects to the next scale [2-5]. Current diagnosis of bone's mechanical state is based on measurements of bone mineral density (BMD). However, not only is the quantity of bone loss important but also the degree and nature of trabecular atrophy. An indication of BMD is not enough for a complete characterization of trabecular deterioration and fracture risk assessment [6].

Fracture mechanical response of cancellous bone may be divided into three different stages: a linear phase where the material deforms reversibly (elastic domain), an elastic-continuum damage mechanics domain where energy is absorbed by the development of diffuse microcracking damage, and a fracture mechanics phase, where the final fracture surfaces are generated [7].

Even with the increase of numerical resources in the last decades, clinical practice demands simple and fast fracture risk assessments. Regarding cancellous bone micro-FE modeling, its heterogeneous microstructure requires of the order of millions of elements so there is a need of compromise be- 
tween accuracy and computational expense for the application of damage and fracture models. Non-linear micro-finite element models have been used in the literature to simulate pre- and post-yielding cancellous bone behavior [8-17]. However, most studies investigate failure initiation without considering propagation and propose complex models requiring parameters hardly measurable. Moreover, there has been little experimental validation of these damage and fracture models. In this context, it is accepted that micro-FE modeling based on high-resolution images is a reliable tool to reproduce the elastic mechanical response and estimate the apparent stiffness of cancellous bone at the microscale [8].

Post-yield behavior was studied from different approaches in the literature. Among continuum plasticity models, Schwiedrzik et al. [11] proposed and validated a cohesive-frictional plasticity model based on Drucker-Prager yield criterion, achieving good correlations with the experimental yield point and stiffness. In [13], García et al. provided a 3D extension of an elastic plastic damage constitutive law for cortical and cancellous bone, which describes three modes of evolution of bone tissue (elastic, pure plastic and damaged plastic) and distinguishes between tensile and compressive damage stresses. However, their study lacks of an experimental validation. On the other hand, O'Connor et al. [12] developed an asymmetric Mises plasticity formulation which was applied to a trabecular network and idealized struts models subjected to tension and compression loading modes.

Regarding fracture mechanics approaches, the Extended Finite Element Method (XFEM) appears with some potential but few studies have been developed on cancellous bone [16, 17], as it has some drawbacks, like requiring 
a degree of freedom enrichment at crack faces and crack tip nodes. The method needs an explicit crack definition, so it can not be used to model fracture initiation, but it could be used coupled with other techniques that address fracture initiation. Moreover, 3D versions present several geometric difficulties.

Continuum damage mechanics approaches may be an interesting option to simulate failure in a simple and precise way. They permit to simulate initiation and propagation of cracks using a smeared crack approach $[9,15$, 18-20]. Under quasi-static loading, isotropic damage laws are well suited to represent the non-linear behavior of cancellous bone [10]. Hambli [9], proposed and validated experimentally an isotropic damage law which is suitable to simulate damage within the trabecular lattice. Complete fracture of the trabeculae was conducted using an element deletion technique.

On the other hand, experimental validation of damage and fracture models is still an issue. For example, visual inspection has not enough accuracy and micro-CT imaging is expensive and time consuming. Commonly used techniques to measure displacements in biological tissues are: displacement gauges (measuring displacements between compression platens), extensometers attached to specimens, loading platen transducers, strain gauges or optical systems [21]. Among them, optical techniques like digital image correlation (DIC) have some advantages over other mentioned techniques. First, it is a non-contact technique, so any damage induced to specimens due to gripping is avoided. In addition, the displacement measurement is local at specimen's surface which prevents compliance effects related to other types of displacement measurements. Furthermore, in case of cancellous bone, the 
microstructure itself acts as a grid of reference points, from which displacements can be estimated. However, this non-speckle approach has scarcely been investigated in the literature [22]. Since the introduction of the DIC method in the 80s [23, 24], significant measurement accuracy improvements have been achieved $[25,26]$ and it has been increasingly used in a wide range of materials in different applications. Recently, a thorough review of its biomechanical applications, potential and limitations was published [27]. DIC can be used to measure full-field displacements and fracture characterization at the organ level [28-30]. However, its application to study damage and fracture of cancellous bone has not been investigated in depth. In this work, DIC is used to study the onset and propagation of damage and to validate the numerical results.

In this paper, we aim to characterize compression fracture of cancellous bone specimens combining DIC and finite element modeling. Previous studies in the literature claim that cancellous bone yield strain is relatively constant and independent of microstructure and apparent density, whereas fracture strain presents higher scattering (between 30 to $40 \%$ ) [2, 31, 32]. These strain parameters are estimated in this study with the purpose of evaluating the observations collected from experiments in the literature through FE modeling. This estimation was accomplished by inverse analysis, taking into account the recorded experimental response of the compression tests. In addition, as a simple experimental technique to validate numerical models is lacking in the literature, the DIC technique is applied for this purpose. To achieve the aforementioned goals, quasi static compression tests were performed on the specimens, which had been previously scanned using micro-CT. The resulting 
images were segmented and a morphometric analysis was performed. Further, we investigated the robustness of the segmentation process, varying the segmentation threshold and studying its influence both on the morphometry and on the apparent stiffness, estimated from the corresponding numerical models. Micro-FE models were generated from micro-CT images to simulate quasi-static compression fracture. A continuum damage mechanics approach was used to model the initiation and evolution of damage at the microscale and the complete fracture of the trabeculae was modeled by means of the element deletion technique. With this procedure, we provide a combined numerical and experimental approach to characterize failure of cancellous bone.

\section{Materials and methods}

\subsection{Cancellous bone specimens preparation}

The trabecular bone samples were prepared from thoracic and lumbar vertebrae of one skeletally mature swine recently euthanised. After extraction, thirteen samples were kept in saline serum at a temperature of $-25^{\circ} \mathrm{C}$. The parallelepiped-shaped samples, whose dimensions were at least $10 \mathrm{~mm}$ side (Fig. 1), were cut out of the vertebral body with a precision saw (Accutom2, Struers, Copenhagen, Denmark). The parameters of the cutting process were the maximum saw blade shaft speed and the minimum saw blade feed (it varied depending upon the original sample morphology). The blade was appropriate to cut materials of hardness $70-400 \mathrm{HV}$. To ensure an accurate sam-

ple face parallelism, several custom-made clamp adaptors were used. Bone marrow was eliminated using an ultrasonic bath and soft water jet. The spec- 
imens were stored in saline serum at temperature $-25^{\circ} \mathrm{C}$ until their scanning and testing following [33]. All the specimens were machined identifying the main trabecular orientation, which later was aligned with the compression test direction.

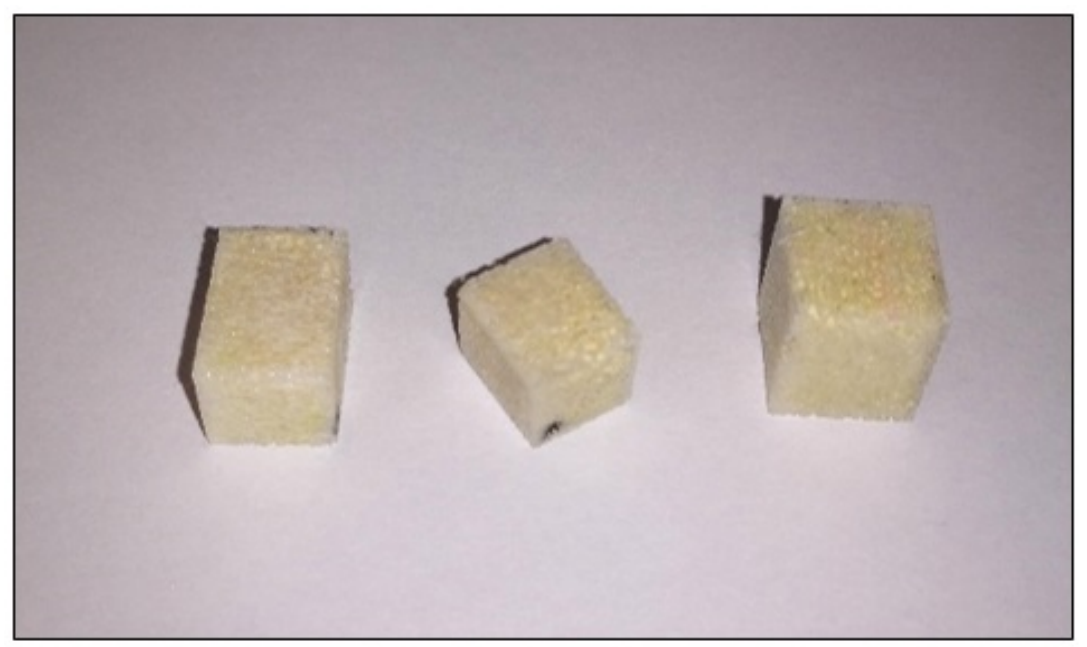

Figure 1: Three of the cancellous bone specimens analyzed in the present study.

\subsection{Micro-CT scanning and segmentation}

Specimens were scanned by micro-CT (V|Tome|X s 240, GE Sensing and Inspection Technologies) using the CENIEH (Burgos, Spain) micro-CT service, with an isotropic voxel resolution of $22 \mu \mathrm{m}$ (voltage $110 \mathrm{kV}$, intensity 280 $\mu \mathrm{A}$, integration time $200 \mathrm{~ms}$, Cu filter). Micro-CT images were segmented using ScanIp software (Simpleware, UK), following a manual thresholding method combined with a connectivity analysis, to avoid groups of voxels non-connected to the main cancellous structure, which otherwise would cause numerical problems in the simulations. The 3D reconstructions of four of the specimens are provided, showing the microstructural description (Fig. 2). 

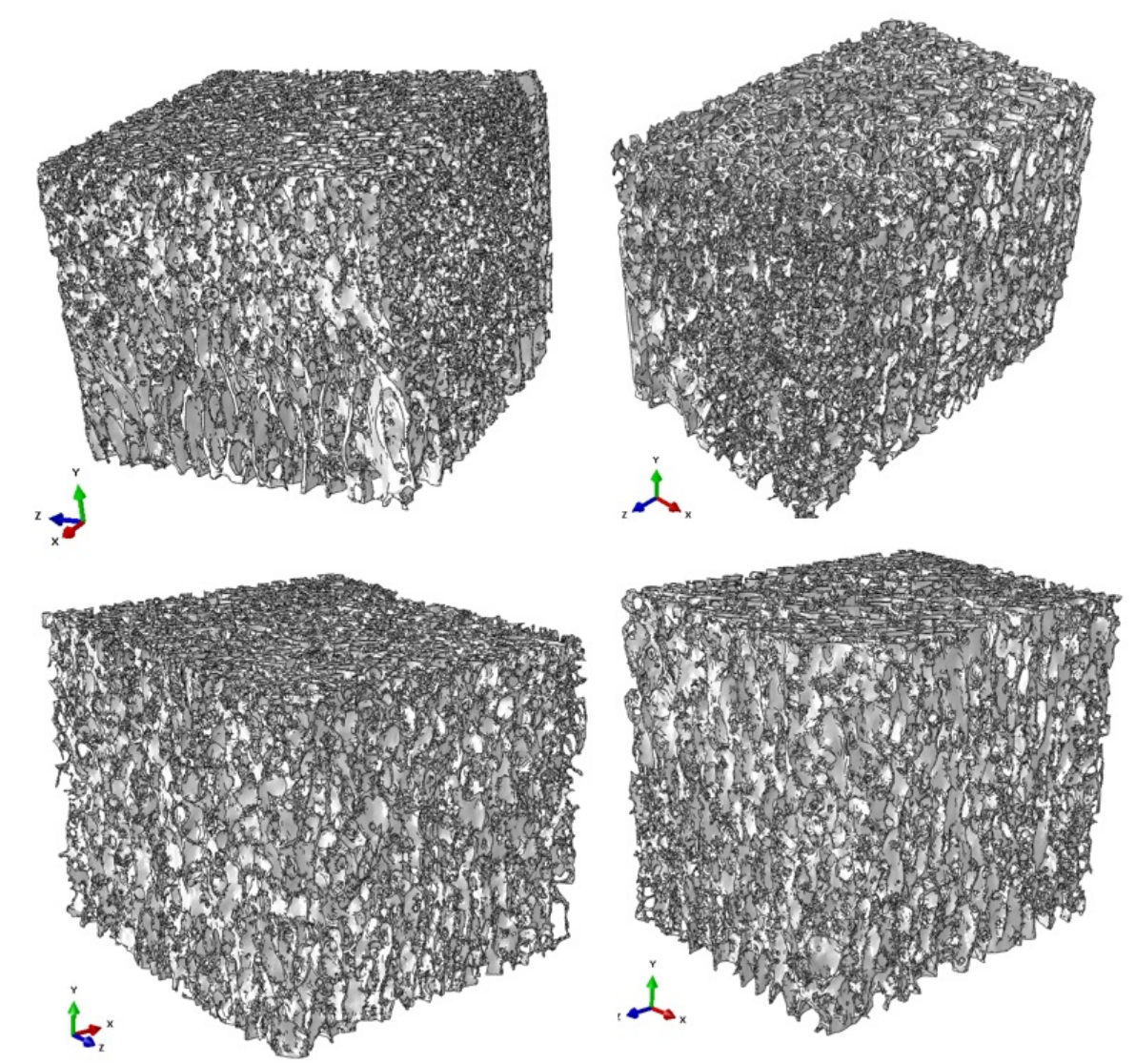

Figure 2: 3D reconstruction of samples 1-4.

\subsection{Experimental compression tests}

Quasi-static compression tests were carried out along the main trabecular orientation to estimate the apparent Young's modulus $\left(E_{\mathrm{compr}}\right)$, the failure stress $\left(\sigma_{\text {fail }}\right)$ and the failure strain $\left(\varepsilon_{\text {fail }}\right)$ of each specimen. The testing protocol is detailed in the following. First, the specimens were thawed at $4^{\circ} \mathrm{C}$ the night previous to testing, maintained moist in $0.9 \%$ saline solution and wrapped in a gauze. Specimens dimensions were determined using a dial caliper. Then, the anisotropy direction was identified and defined as the test- 
ing direction. Compression tests were conducted using an electromechanical testing machine (MTS Criterion C42, MTS Systems, USA), with aluminum compression platens (MTS ref.: FYA502A) and measuring the displacement between compression platens using a displacement gauge (MTS ref.:632.06H20). Due to the small specimens dimensions, positioning the displacement gauge between compression platens could cause damage to it. In order to avoid any damage during testing, a metal surface was added to the lower compression platen where the displacement gauge contact point was positioned (Fig. 3). A $10 \mathrm{~N}$ pre-load was defined. Then, load was applied after 10 preconditioning cycles [34] with a displacement rate of $1 \mathrm{~mm} / \mathrm{min}$ between $0.1 \%$ to $0.35 \%$ strain levels, to avoid damage within specimens. Experimental artifacts from different sources were minimized following recommendations given in [35]. However, different levels of damage at the specimen-compression platen interface was observed in some cases, due to the cut of the trabeculae at the machined surfaces of the specimen [36, 37]. Three specimens that suffered from experimental artifacts, related to stress concentrations due to non-parallel faces leading to crushing at the edges, were discarded from the study. Therefore, ten samples were used in the following study. The apparent Young's modulus $\left(E_{\text {compr }}\right)$ was determined as a linear fit in the last cycle from the stress-strain response. The apparent failure stress $\left(\sigma_{\text {fail }}\right)$ was defined as the peak value of the stress following the elastic response and the apparent failure strain $\left(\varepsilon_{\text {fail }}\right)$ was defined as the strain at $\sigma_{\text {fail }}$.

\subsection{Digital Image Correlation: application to cancellous bone}

Our application of DIC technique to cancellous bone specimens aims at characterizing its fracture initation and propagation during quasi-static com- 


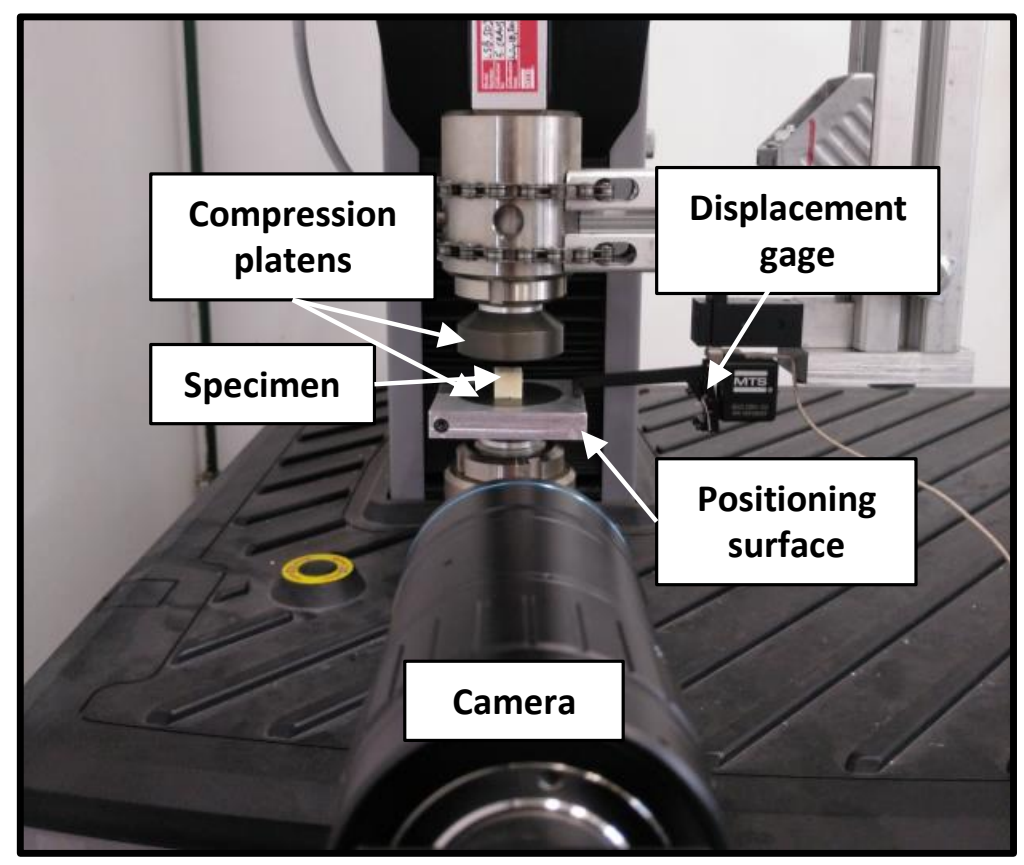

Figure 3: Experimental setup for the compression tests and digital image correlation (DIC) system.

pression testing. Fig. 4 shows a scheme of the DIC procedure. We analyzed different variables to investigate the best fracture descriptor. Specifically, we computed: maximum principal strain $\left(\varepsilon_{1}\right)$, shear strain $\left(\tau_{12}\right)$ and equivalent strain $\left(\varepsilon_{\text {eq }}\right)$ defined by Eq. (3). In order to apply this technique, we used VIC-2D Digital Image Correlation software (v.6.0.2 Correlated Solutions Inc., US), a high resolution fixed focal lens (HF7518V-2, Myutron, Japan) with $12 \mathrm{Mpx}$ resolution and $75 \mathrm{~mm}$ focal length, and a spotlight.

The region of interest (ROI) was selected to analyze the whole specimen and ensuring a perpendicular relative position between the camera and the specimen to avoid out-of-plane displacements during testing. We per- 


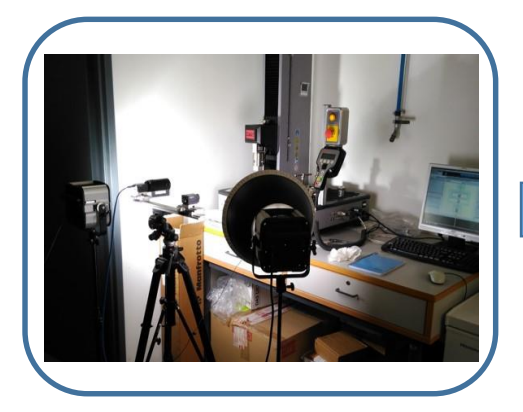

\section{Acquisition of digital images during compression testing}

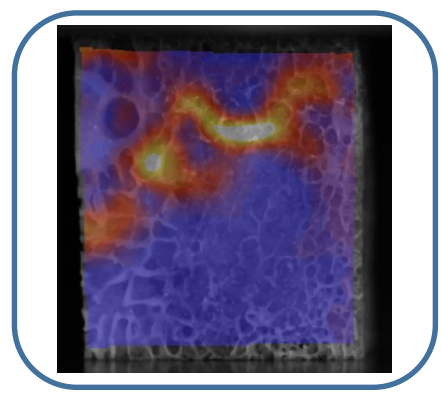

Strain field

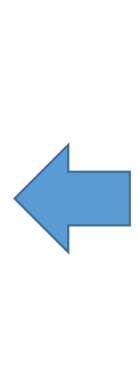
Image analysis based on pattern matching criterion

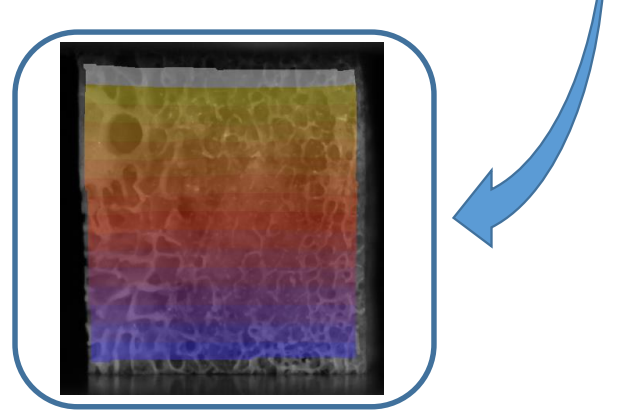

Displacement field

Figure 4: Scheme of digital image correlation (DIC) procedure. DIC is applied to the images acquired during testing, which are analyzed based on a pattern matching criterion, resulting in the displacement field estimation. The strain field is computed according to the chosen tensorial description.

formed a non-speckle approach, as specimens microstructure was used as a grid to compute displacements during testing. As fracture involves trabeculae displacements and rotations, we used an incremental correlation, where displacement correlation is not estimated from the reference image but in the subsequent ones. A square facet (the grid in which ROI is divided) of size 
125 pixels was used to minimize calculation errors and a step size (distance between two consecutive facets) of 7 pixels was set. To ensure the highest sub-pixel accuracy, a high order interpolation spline method (8-tap) was applied. The correlation criterion chosen is the normalized square differences as it tends to be the most robust [38].

\subsection{Microstructural characterization}

To characterize specimens microstructure, we estimated the following parameters using an in-house developed procedure in Matlab (version R2018b, Massachusetts, USA): bone volume fraction (BV/TV), bone surface per total volume (BS/TV), bone surface to volume ratio (BS/BV), mean trabecular thickness (Tb.Th), mean trabecular separation (Tb.Sp), trabecular number (Tb.N), fractal dimension (D2D, D3D) and the anisotropy degree (DA $\mathrm{MIL}_{\text {) }}$ estimated through 3D mean intercept length [39].

Associations between morphometry and mechanical response elastic and ultimate parameters were explored. We used Matlab to calculate linear regressions between each pair of variables, reporting correlation coefficients and pointing out the relationships significant at a $95 \%$, with p-values lower than 0.05 .

\subsection{Micro-finite element modeling}

Finite element models of five of the specimens were generated from the micro-CT images, reproducing with great accuracy the heterogeneous microstructure of cancellous bone. Micro-FE meshes were created using ScanIp

Software (Simpleware, UK), leading to meshes between 0.9M and 2.5M nodes and $2.8 \mathrm{M}$ and $8.2 \mathrm{M} 3 \mathrm{D}$ linear elements (C3D4 in Abaqus). 


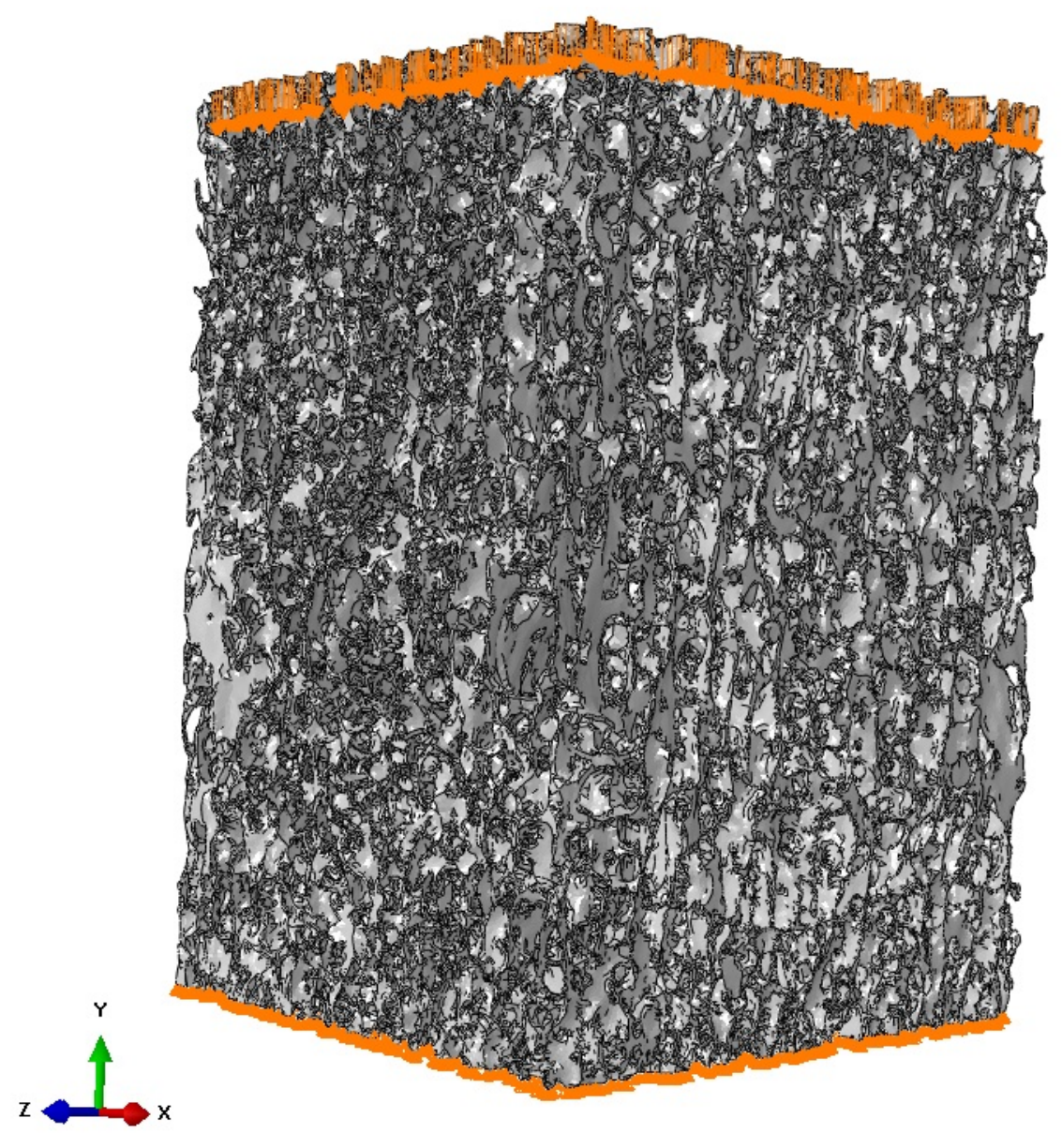

Figure 5: Boundary conditions scheme: experimentally measured displacement was prescribed at the upper face nodes of each model, while the bottom face nodes were constrained in the compression direction.

The behavior of cancellous bone tissue at trabecular level was modeled as a homogeneous isotropic linear-elastic material. This assumption is sufficient to estimate the apparent stiffness of cancellous bone [40]. The Young's modulus at the tissue level $E_{i}$ (i.e. trabecular level) used in the micro-FE models 
was estimated by inverse analysis using the experimental test data. This way, $E_{i}$ was calculated for each sample so that the stiffness of the numerical models matched the experimental measurements.

Boundary conditions were defined to mimic the experimental unconfined compression tests, so the nodes in the lower surface were constrained in the test direction. The experimentally recorded displacement was prescribed at the nodes of the upper surface (Fig. 5).

\subsection{Compression failure modeling}

In this work, compression failure is modeled following a continuum damage mechanics approach. Complete fracture at the microscale subsequent to damage is modeled by means of the element deletion technique.

In the framework of a continuum damage approach, failure is modeled as the degradation of the mechanical properties when critical values are reached. This is accomplished using an Abaqus user's subroutine (USDFLD), whereby a material degradation is introduced to describe the progressive loss of stiffness due to the propagation and coalescence of microcracks, microvoids and similar defects. These changes in the microstructure lead to a material stiffness degradation observed in the macroscale [41]. Bone failure process is controlled by strains, as reported in [42], so our approach is based on an equivalent strain, Eq. (3).

In the quasi-static regime, the isotropic relation of elasticity under a damage mechanics approach is expressed by [20]:

$$
\sigma_{i j}=(1-D) C_{i j k l} \varepsilon_{k l}
$$


where $D$ is the damage variable, $\sigma_{i j}, \varepsilon_{k l}$ are the stress and strain tensors and $C_{i j k l}$ is the constitutive elastic tensor.

Following $[9,15]$, at the tissue level we consider an isotropic damage law experimentally fitted, that is be expressed in a power form:

$$
D= \begin{cases}0 & \varepsilon_{\mathrm{eq}} \leq \varepsilon_{\mathrm{y}, \mathrm{c}} \\ D_{c} \varepsilon_{\mathrm{eq}}^{n} & \varepsilon_{\mathrm{y}, \mathrm{c}}<\varepsilon_{\mathrm{eq}}<\varepsilon_{\mathrm{f}, \mathrm{c}} \\ D_{c} & \varepsilon_{\mathrm{eq}} \geq \varepsilon_{\mathrm{f}, \mathrm{c}}\end{cases}
$$

based on an equivalent strain, Eq. (3)

$$
\varepsilon_{\mathrm{eq}}=\sqrt{\frac{2}{3} \varepsilon_{i j} \varepsilon_{i j}}
$$

In order to avoid mesh dependence on damage propagation, we performed a linear weighting of the strain at fracture as a function of the characteristic micro-FE length $\left(L_{\mathrm{FE}}\right)$ and the characteristic crack length for cancellous bone $\left(L_{\text {frx }}\right)[15]$, see Eq. (4). $L_{\mathrm{FE}}$ is computed at each iteration for each element during simulation and it is provided by Abaqus (referred as CELENT Abaqus code variable). As average crack lengths reported in the literature for cancellous bone range from 50 to $100 \mu \mathrm{m}$, we take the characteristic crack length as $L_{\mathrm{frx}}=0.075 \mathrm{~mm}[43,44]$. Then, for computing purposes, the strain at fracture $\varepsilon_{\mathrm{f}}$ at each element is considered as:

$$
\varepsilon_{\mathrm{f}}=\varepsilon_{\mathrm{f}, \mathrm{c}}\left(\frac{L_{\mathrm{frx}}}{L_{\mathrm{FE}}}\right)
$$

Table 1 presents the material bone mechanical properties used for the finite element simulations in this work. Note that calibrated values are inferred from FE models by inverse analysis. Young's moduli at tissue level 
were calibrated to match the experimental elastic response for each specimen and, similarly, the yield strain in compression was calibrated so that the numerical post-yield response matched the experimentally recorded one.

Table 1: Material properties defined to simulate fracture with image-based micro-FE models. Young's modulus expressed as mean \pm SD.

\begin{tabular}{lccc} 
Parameters & Notation & Value & Reference \\
\hline Young's modulus & $E[\mathrm{GPa}]$ & $10.76 \pm 3.07$ & Calibrated \\
Poisson's ratio & $\nu[-]$ & 0.3 & Literature $[45]$ \\
Yield strain in compression & $\varepsilon_{\mathrm{y}, \mathrm{c}}[\%]$ & 0.68 & Calibrated \\
Strain at fracture in compression & $\varepsilon_{\mathrm{f}, \mathrm{c}}[\%]$ & $4.0 \pm 0.96$ & Calibrated \\
Critical damage at fracture in compression & $D_{c}$ & 0.95 & Literature $[18,19]$ \\
Damage exponent & $\mathrm{n}$ & 2 & Literature $[46]$ \\
Characteristic crack length & $L_{\mathrm{frx}}[\mathrm{mm}]$ & 0.075 & Literature $[43,44]$ \\
\hline
\end{tabular}

\section{Results and discussion}

\subsection{Stress-strain relationships recorded in quasi-static compression tests}

The force-displacement mechanical response recorded in experimental tests was employed to compute the stress-strain relationships which are presented in Fig. 6. As mentioned in Section 2.3, the specimens that suffered from experimental artifacts were discarded from the study and their results are not presented. The preconditioning cycles followed by monotonic testing until complete failure can be observed. Table 2 summarizes the apparent compression stiffness $\left(E_{\text {compr }}\right)$, apparent stress at failure $\left(\sigma_{\text {fail }}\right)$ and apparent strain at failure $\left(\varepsilon_{\text {fail }}\right)$ measured through experimental tests. 


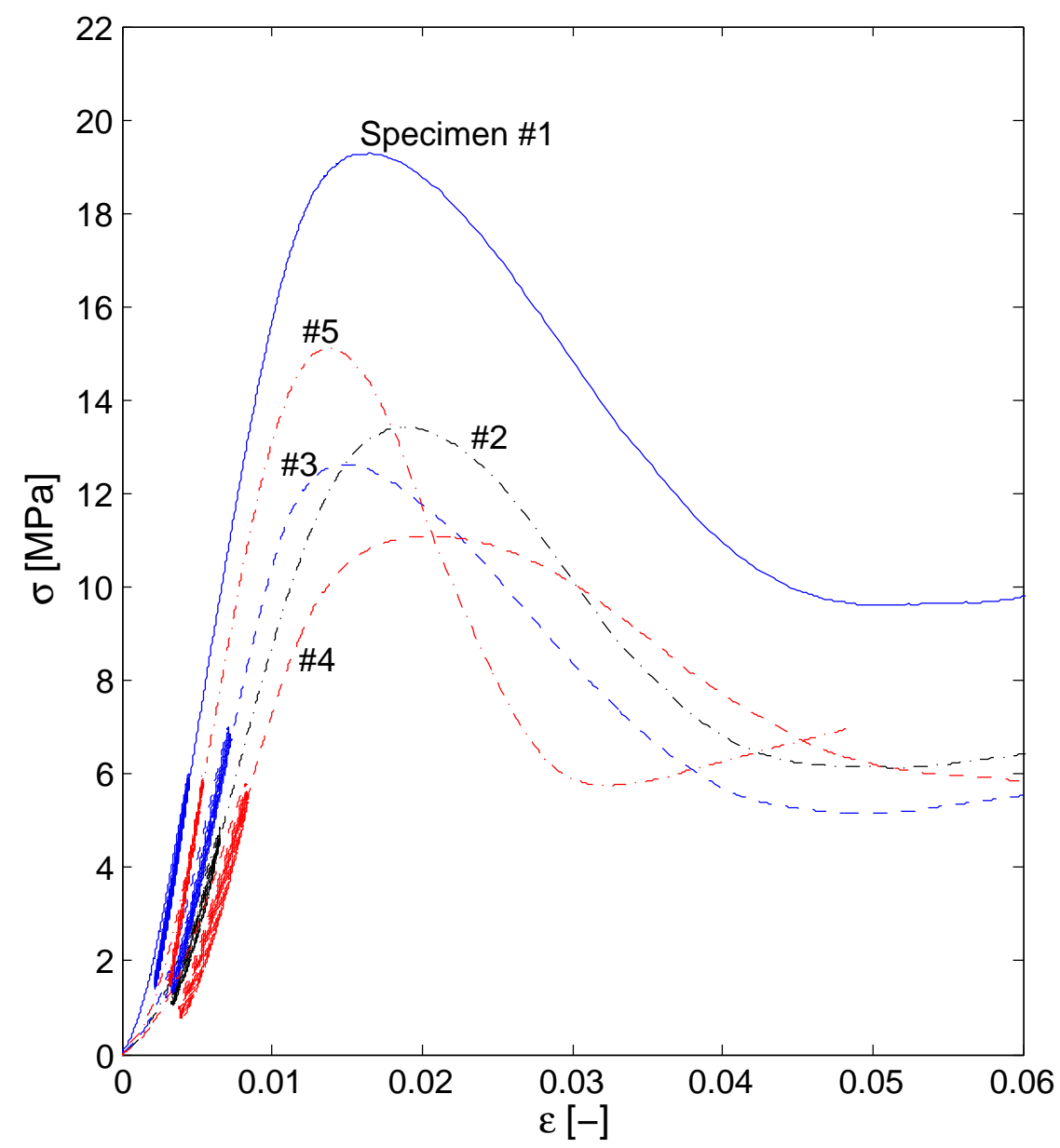

Figure 6: Stress-strain relationships recorded in the quasi-static compression tests for 5 of the 10 specimens under study. The preconditioning cycles followed by monotonic compression until fracture can be observed.

\subsection{Relationships between microstructural parameters defining cancellous bone} specimens and experimental compression tests

Table 3 presents the parameters defining the microstructural features of each specimen. As commented in Section 2.5, we estimated volume fraction 
Table 2: Mechanical parameters measured in experimental quasi-static compression tests.

\begin{tabular}{lccc} 
& $E_{\text {compr }}[\mathrm{MPa}]$ & $\sigma_{\text {fail }}[\mathrm{MPa}]$ & $\varepsilon_{\text {fail }}[\%]$ \\
\hline Specimen \#1 & 1943.8 & 19.3 & 1.65 \\
Specimen \#2 & 1118.4 & 13.4 & 1.93 \\
Specimen \#3 & 1481.8 & 12.6 & 1.49 \\
Specimen \#4 & 1078 & 11.1 & 2.07 \\
Specimen \#5 & 1915.3 & 15.1 & 1.38 \\
Specimen \#6 & 879.2 & 10.5 & 1.9 \\
Specimen \#7 & 1416.1 & 14.7 & 1.65 \\
Specimen \#8 & 909.5 & 9.2 & 1.75 \\
Specimen \#9 & 927.3 & 8.8 & 1.53 \\
Specimen \#10 & 982.3 & 9.2 & 1.45 \\
\hline Mean & 1265.2 & 12.4 & 1.68 \\
\hline SD & 405.4 & 3.3 & 0.23 \\
\hline
\end{tabular}

$(\mathrm{BV} / \mathrm{TV})$, bone surface to volume ratio $(\mathrm{BS} / \mathrm{BV})$, mean trabecular thickness (Tb.Th), mean trabecular separation (Tb.Sp), trabecular number (Tb.N), fractal dimension $\left(\mathrm{D}_{2 \mathrm{D}}, \mathrm{D}_{3 \mathrm{D}}\right)$ and the anisotropy degree estimated through 3D mean intercept length $\left(\mathrm{DA}_{\mathrm{MIL}}\right)$.

It can be observed that some parameters do not vary much for the set of samples analyzed. For example, values for Tb.Th in Table 3 show little variations because the specimens were harvested from only two subjects.

Linear regressions were estimated between parameters defining specimen microstructure and the experimentally measured compression stiffness $\left(E_{\text {compr }}\right)$, stress at failure $\left(\sigma_{\text {fail }}\right)$ and strain at failure $\left(\varepsilon_{\text {fail }}\right)$. The correlation coefficients of the relationships under study are presented in Table 4. Fig. 7 
Table 3: Morphometric analysis of specimens under study. BV/TV=bone volume fraction, $\mathrm{BS} / \mathrm{TV}=$ bone surface per total volume, $\mathrm{BS} / \mathrm{BV}=$ bone surface per bone volume, $\mathrm{Tb} . \mathrm{Th}=$ mean trabecular thickness, $\mathrm{Tb} . \mathrm{Sp}=$ mean trabecular separation, $\mathrm{Tb} . \mathrm{N}=$ trabecular number, $\mathrm{D}_{2 \mathrm{D}}=$ fractal dimension $2 \mathrm{D}, \mathrm{D}_{3 \mathrm{D}}=$ fractal dimension $3 \mathrm{D}, \mathrm{DA}_{\mathrm{MIL}}=$ bone degree of anisotropy estimated through mean intercept length.

\begin{tabular}{llllllllll} 
Specimen & \multicolumn{3}{l}{ BV/TV BS/TV BS/BV Tb.Th } & Tb.Sp & Tb.N & $D_{2 \mathrm{D}}[-]$ & $\mathrm{D}_{3 \mathrm{D}}[-]$ & DA $_{\text {MIL }}[-]$ \\
& {$[\%]$} & {$\left[\mathrm{mm}^{-1}\right]$} & {$\left[\mathrm{mm}^{-1}\right]$} & {$[\mathrm{mm}]$} & {$[\mathrm{mm}]$} & {$\left[\mathrm{mm}^{-1}\right]$} & & & \\
\hline$\# 1$ & 27.07 & 4.66 & 19.2 & 0.16 & 0.56 & 1.67 & 1.64 & 2.72 & 1.74 \\
$\# 2$ & 20.47 & 5.34 & 23.9 & 0.14 & 0.56 & 1.47 & 1.62 & 2.69 & 1.53 \\
$\# 3$ & 17.63 & 4.48 & 25.43 & 0.13 & 0.59 & 1.34 & 1.63 & 2.68 & 1.68 \\
$\# 4$ & 22.6 & 5.31 & 23.49 & 0.14 & 0.41 & 1.59 & 1.71 & 2.74 & 1.52 \\
$\# 5$ & 24.73 & 5.29 & 21.39 & 0.14 & 0.5 & 1.79 & 1.69 & 2.77 & 1.68 \\
$\# 6$ & 18.01 & 5.74 & 31.89 & 0.14 & 0.69 & 1.32 & 1.51 & 2.60 & 1.68 \\
$\# 7$ & 23.44 & 7.43 & 31.72 & 0.13 & 0.54 & 1.80 & 1.59 & 2.70 & 1.59 \\
$\# 8$ & 19.99 & 5.44 & 27.20 & 0.12 & 0.57 & 1.67 & 1.56 & 2.66 & 1.41 \\
$\# 9$ & 17.25 & 6.03 & 34.95 & 0.13 & 0.68 & 1.33 & 1.50 & 2.57 & 1.59 \\
$\# 10$ & 19.66 & 6.69 & 34.02 & 0.13 & 0.60 & 1.51 & 1.56 & 2.64 & 1.61 \\
\hline Mean & 21.09 & 5.64 & 27.32 & 0.14 & 0.57 & 1.55 & 1.60 & 2.68 & 1.60 \\
\hline SD & 3.28 & 0.89 & 5.52 & 0.01 & 0.08 & 0.18 & 0.07 & 0.06 & 0.10 \\
\hline
\end{tabular}

plots the most significant correlations obtained for each mechanical property. $E_{\text {compr }}$ and $\sigma_{\text {fail }}$ correlate well with bone volume fraction $(\mathrm{BV} / \mathrm{TV})$ as reported in other works $[2,47,48]$. This could be expected because of the linear relationship between $E_{\text {compr }}$ and $\sigma_{\text {fail }}$ [2]. A negative correlation is observed between $\mathrm{BS} / \mathrm{BV}$ and $\sigma_{\text {fail }}$. It suggests that the thinner the trabeculae are, the lower is the stress at failure for the overall structure, which is consistent with the regression between Tb.Th and stress at failure. Fractal dimension in both $2 \mathrm{D}$ and $3 \mathrm{D}$ versions present a significant correlation with the apparent modulus. A higher value of fractal dimension is related to increasing $E_{\text {compr }}$ 
Table 4: Correlation of the linear regressions estimated between morphometric and failure parameters.

\begin{tabular}{l|ccc} 
& \multicolumn{3}{|c}{ Correlation coeficient $\left(R^{2}\right)$} \\
\hline & $E_{\text {compr }}$ & $\sigma_{\text {fail }}$ & $\varepsilon_{\text {fail }}$ \\
\hline $\mathrm{BV} / \mathrm{TV}$ & $\mathbf{0 . 5 8 2}$ & $\mathbf{0 . 6 7 9}$ & 0 \\
$\mathrm{BS} / \mathrm{TV}$ & 0.128 & 0.09 & 0.011 \\
$\mathrm{BS} / \mathrm{BV}$ & 0.489 & $\mathbf{0 . 5 0 7}$ & 0.025 \\
Tb.Th & 0.35 & $\mathbf{0 . 5 7 3}$ & 0.033 \\
Tb.Sp & 0.145 & 0.12 & 0.068 \\
Tb.N & 0.298 & 0.269 & 0.016 \\
$\mathrm{D}_{2 \mathrm{D}}$ & $\mathbf{0 . 5 2 4}$ & 0.448 & 0.001 \\
$\mathrm{D}_{3 \mathrm{D}}$ & $\mathbf{0 . 5 2 1}$ & 0.447 & 0.001 \\
$\mathrm{DA}_{\text {MIL3D }}$ & 0.397 & 0.32 & 0.191 \\
\hline
\end{tabular}

value. Both parameters present a positive linear correlation with a $R^{2}$ value of 0.52 .

On the other hand, strain at fracture does not show correlation to any of the morphometric parameters analyzed. This results are in line with observations reported in the literature, which claim that failure strain is independent from microstructure and density $[2,47]$. This observation supports the initial hypothesis of this paper. Finally, other parameters such as BS/TV, Tb.Sp, Tb.N or DA $\mathrm{DIL}_{\mathrm{L}}$ showed no correlation with the mechanical properties.

3.3. Influence of segmentation on microstructural description and elastic response

Cancellous bone segmentation often depends on the user's segmentation criterion. As manual thresholding is commonly used to segment cancellous 

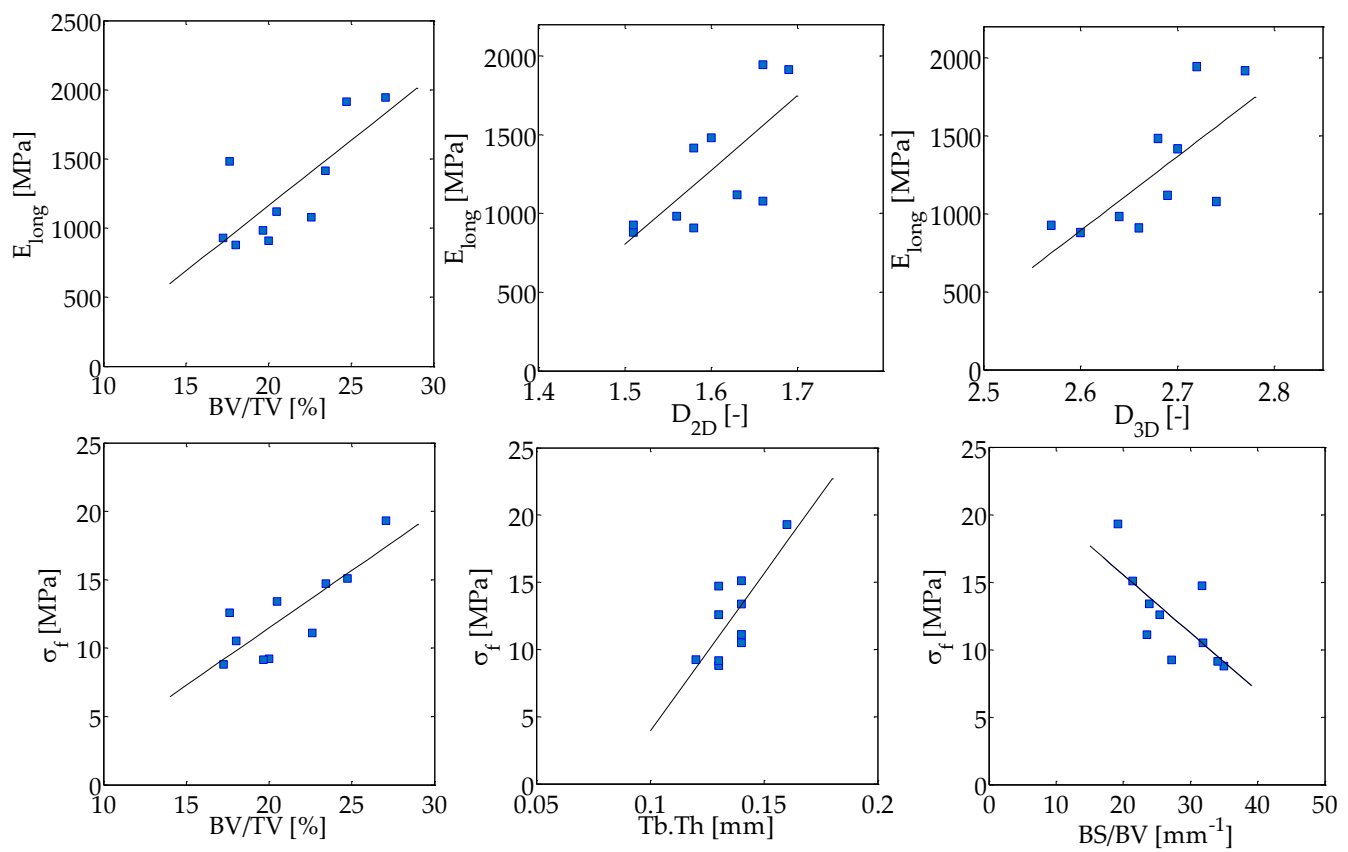

Figure 7: Relationships between morphometric parameters and mechanical properties with the highest correlation coefficient. The associations are significant for confident interval of $95 \%$ (p-value $<0.05)$.

bone micro-CT images, slight variations on the selected threshold may have important effects on the microstructural description estimations and the elastic response of the finite element models generated from the segmented masks. In this section, we study the influence of segmentation threshold variation from the user's choice in a range of $\pm 15 \%$ on the microstructural parameters estimation and the compression stiffness calculation.

Fig. 8 shows a detail of the masks resulting from a $\pm 15 \%$ threshold variation for Specimen \#3 where it can be noticed the small differences between the segmented masks. Similar influence is expected for other cancellous bone 
samples.

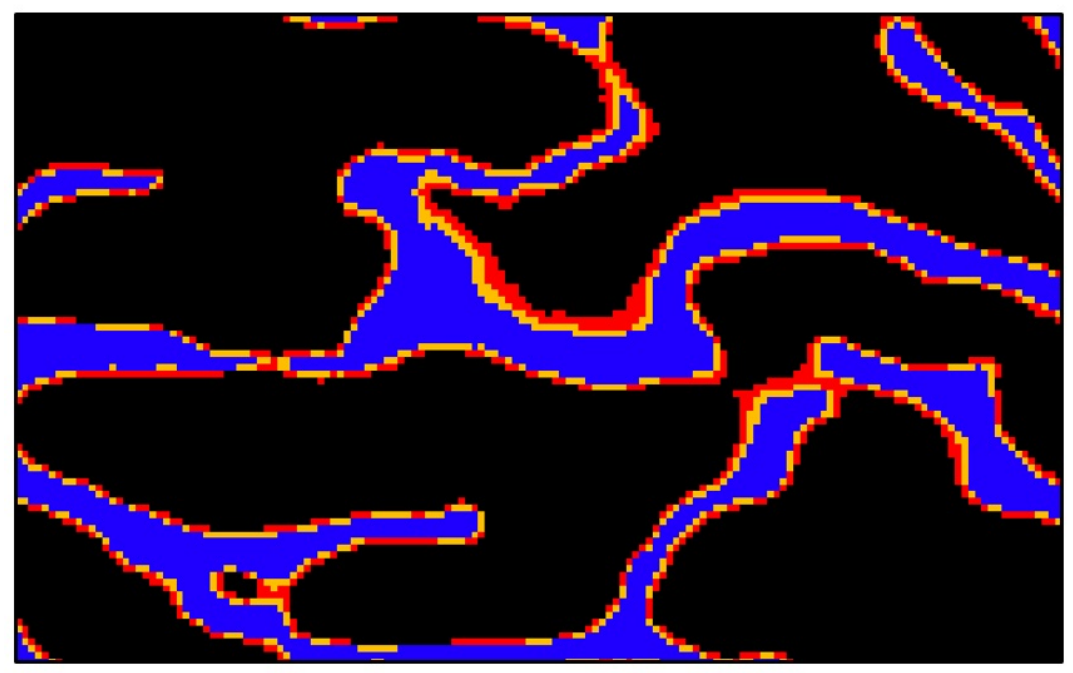

Figure 8: Detail of segmented masks varying the segmentation threshold $\pm 15 \%$ from the user's choice. Slight differences between masks can be noticed (in blue: $+15 \%$ threshold variation, in yellow: original threshold, in red: $-15 \%$ threshold variation).

The influence of the segmentation threshold variation on the microstructural parameters and compression stiffness estimations is presented in Fig. 9. The most sensitive parameters to segmentation threshold variations are $E_{\text {compr }}, \mathrm{BV} / \mathrm{TV}, \mathrm{BS} / \mathrm{BV}$ and Tb.N with variations of at least $16 \%$. For example, $E_{\text {compr }}$ suffers from variations up to $\pm 42 \%$ when the segmentation threshold varies $\pm 15 \%$.

Some parameters, such as BS/TV, Tb.Sp, $\mathrm{D}_{2 \mathrm{D}}$ and $\mathrm{D}_{3 \mathrm{D}}$ are more robust to segmentation. This study reveals an influence lower than $5 \%$ for all of them for a $\pm 15 \%$ threshold variation.

On the other hand, anisotropy degree is less sensitive to segmentation threshold variation in a certain range but, as we increase the threshold, the 
trabeculae become slenderer and therefore, more oriented, leading to a less isotropic behavior. In case of a 15\% increase of threshold, the anisotropy degree increases more than $10 \%$, but this effect is negligible for a $-15 \%$ threshold, as the trabeculae thicken and the structure behaves more isotropically.

This study reveals that segmentation has major importance on the compression stiffness estimation through micro-FE modeling, with up to $42 \%$ variation on the estimated $E_{\text {compr }}$ when decreasing $-15 \%$ the segmentation threshold. Also, the microstructural description is affected by the segmentation threshold choice, being more relevant for parameters such as bone volume fraction, which is often used to estimate cancellous bone quality.

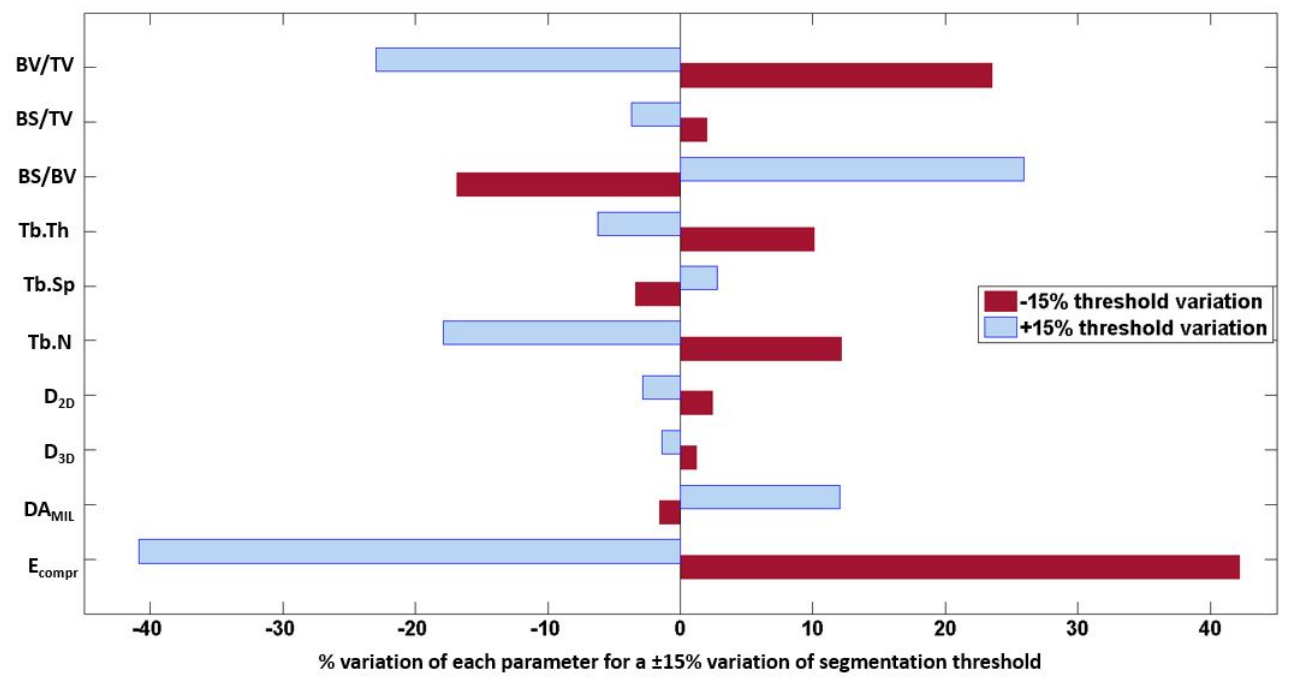

Figure 9: Sensitivity analysis. Influence of varying the user's choice segmentation threshold $\pm 15 \%$ on the microstructural parameters and the apparent compression stiffness estimated from image-based micro-FE models.

Our results about the influence of the segmentation on the morphometric and apparent stiffness are in line with others reported in the literature 
$[49,50]$. For example, the same effect is investigated but within a smaller threshold variation $( \pm 1 \%)$, obtaining the same trends for the same range of BV/TV, except for the case of the anisotropy degree [49]. As we study a wider range of threshold variation $( \pm 15 \%)$, the anisotropy degree $\mathrm{DA}_{\mathrm{MIL}}$ increases as the trabeculae become more slender and, as a consequence, the global behavior is less isotropic.

The effect of segmentation variation when performed by different users is presented. Variations up to $13 \%$ of the selected threshold are reported [50], so our threshold variation $\pm 15 \%$ is of the order of the typical user random errors.

\subsection{Fracture patterns using DIC}

The DIC procedure was applied to the five samples numerically modeled and tested with no experimental artifacts to obtain the subsequent displacement fields during loading. Then, different strain-based fields were computed to determine the most suitable parameter to characterize trabecular bone fracture in a qualitative way. Three field variables were studied. The first two are provided by default by the processing software: maximum principal strain $\varepsilon_{1}$ and shear strain $\tau_{12}$. The third one was manually implemented and corresponds to the equivalent strain defined by Eq. (3).

A comparison between DIC and displacement gauge measurements is shown (Fig. 10). Both metrics nearly match with a maximum measurement difference of $0.03 \mathrm{~mm}$.

Figure 11 shows the results obtained after the analysis of Specimens \#1 (top) to \#5 (bottom). As can be observed in Fig.11 a), $\tau_{12}$ gives an indication of failure location, but not as accurately as with the rest of candidate mag- 


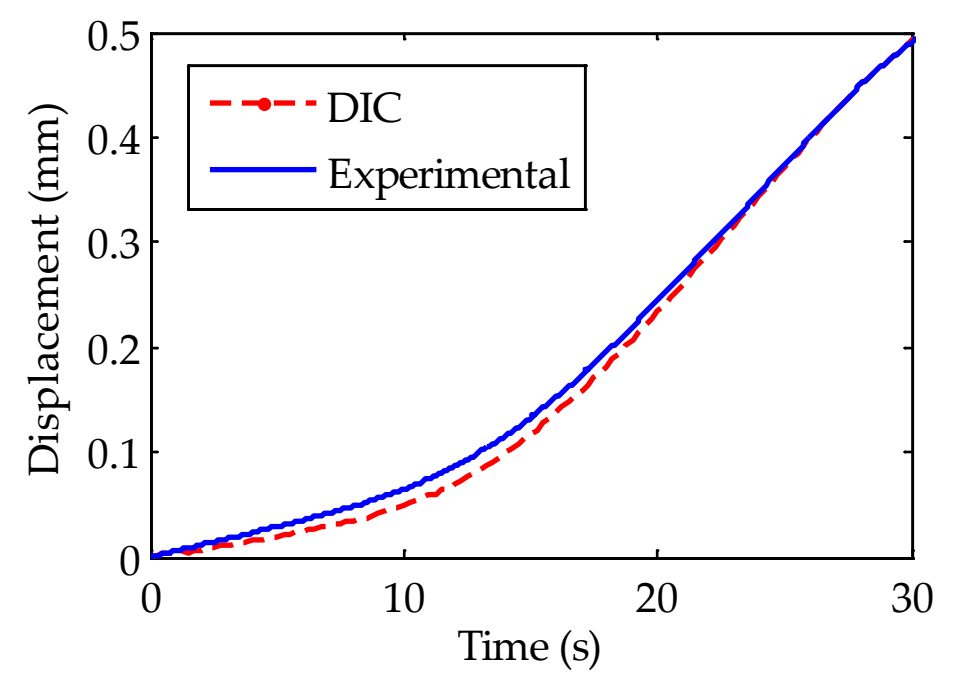

Figure 10: Displacement signal measured with testing machine displacement gauge and DIC.

nitudes. In the literature, there is agreement in that shear bands and strain localization are observed in cancellous bone compression fracture, highlighting the importance of shear properties to avoid shear failure mechanisms [51-53]. Despite the fact that shear strain concentrations arise in the fracture area, they do not fully represent the experimental fracture pattern, so we conclude that $\tau_{12}$ is not the best descriptor of compression fracture in cancellous bone specimens. This may be explained by the homogenized nature of DIC which makes this phenomenon more diffuse than for the other variables analyzed.

Column b) in Fig. 11 shows $\varepsilon_{\text {eq }}$ strain fields. Despite $\varepsilon_{\text {eq }}$ is an invariant and it does not give information about the failure mode, it takes into account both the normal and shear contributions and it seems to be the best option in order to predict the fracture region. As can be seen in Fig. 11 bottom, 

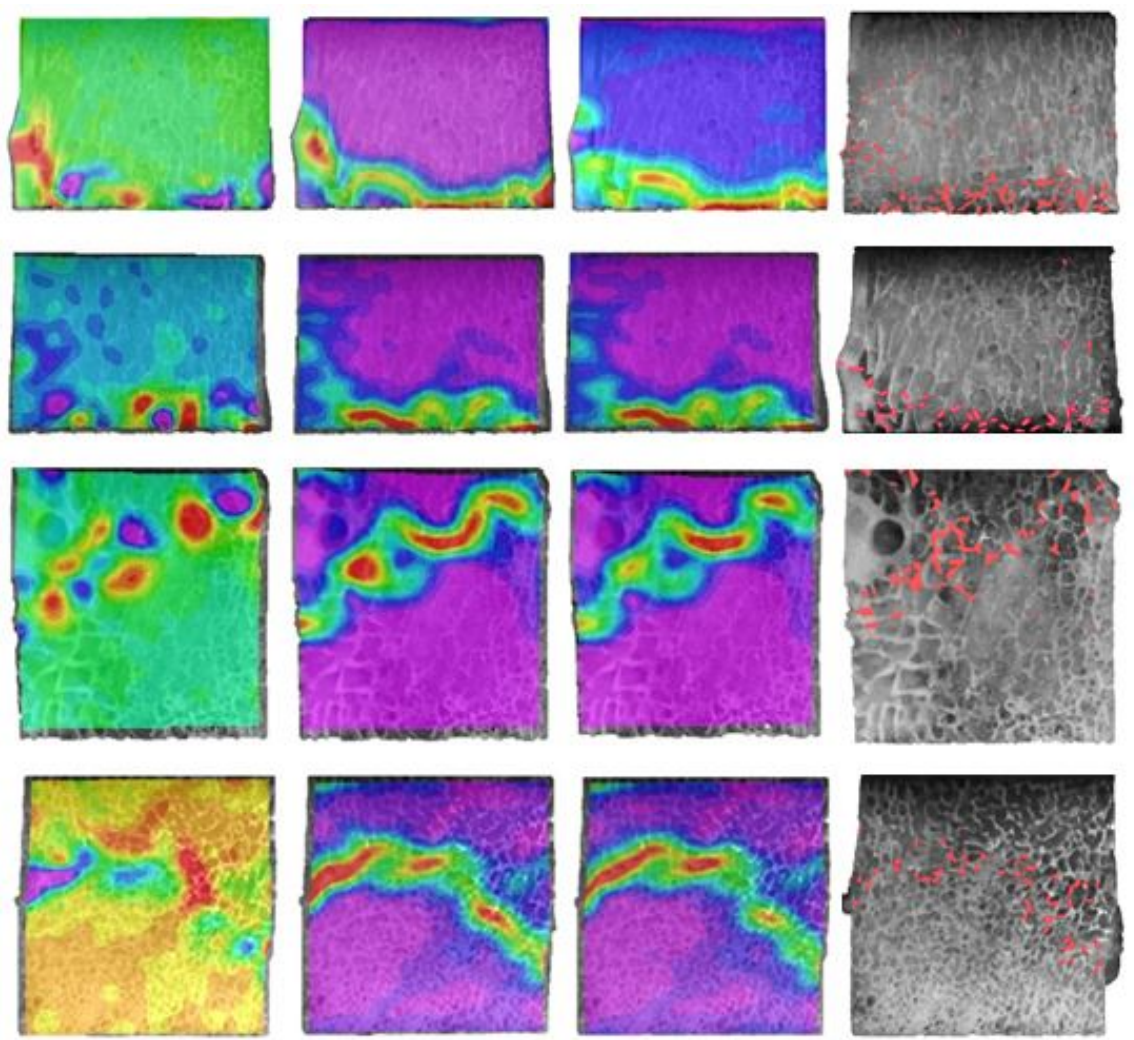

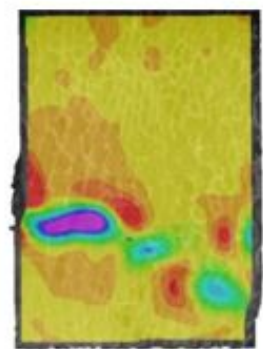

a)

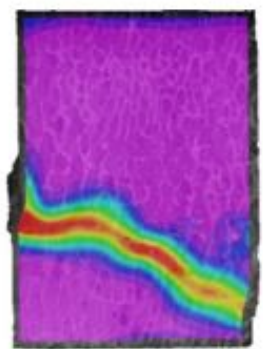

b)

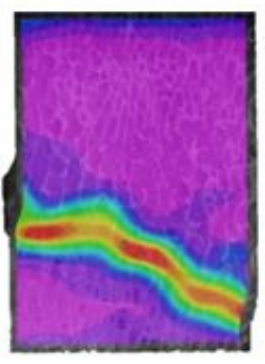

c)

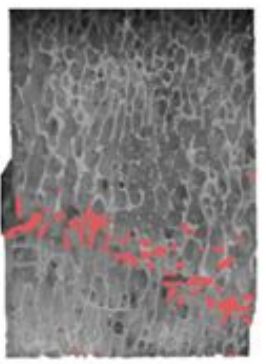

d)

Figure 11: Computed strain fields using DIC for all specimens ordered from \#1 (top) to \#5 (bottom). a) $\tau_{12}$, b) $\varepsilon_{\text {eq }}$, c) $\varepsilon_{1}$ and d) experimental fracture pattern marked in red.

the strain field corresponding to $\varepsilon_{1}$ detects tensile stresses associated with a region undergoing bending stresses due to local buckling (left side of \#2 
Fig. 11, bottom, c). Nonetheless, the failure that is occurring in this zone is not directly characterized with this variable. Therefore, $\varepsilon_{1}$ is suitable to distinguish tension/compression modes but is not as representative as $\varepsilon_{\text {eq }}$ to predict fracture patterns.

\subsection{Fracture properties estimation using micro-FE models}

Quasi-static compression simulations were performed using micro-FE models. To extract the optimal fracture parameters (compression yield strain $\left(\varepsilon_{\mathrm{y}, \mathrm{c}}\right)$ and strain at compression fracture $\left.\left(\varepsilon_{\mathrm{f}, \mathrm{c}}\right)\right)$ to reproduce the experimental response, a parametric study was carried out. The best correlation between the experimental force-displacement curve and the simulated one was achieved by applying the parameters summarized in Table 5. Fig. 12 presents a comparison between the experimental and the numerical force-displacement response. The approach proposed in this work is capable of reproducing the quasi-static compression tests.

Table 5: Fracture parameters obtained from micro-FE simulations of quasi-static compression.

\begin{tabular}{ccc} 
& $\varepsilon_{\mathrm{y}, \mathrm{c}}$ & $\varepsilon_{\mathrm{f}, \mathrm{c}}$ \\
\hline Specimen \#1 & 0.0068 & 0.0410 \\
Specimen \#2 & 0.0068 & 0.0525 \\
Specimen \#3 & 0.0068 & 0.0320 \\
Specimen \#4 & 0.0068 & 0.0450 \\
Specimen \#5 & 0.0068 & 0.0290 \\
\hline
\end{tabular}

The yield strain values calculated are suitable for all the sample and are similar to other values reported in the literature. For example, Hambli [9] 


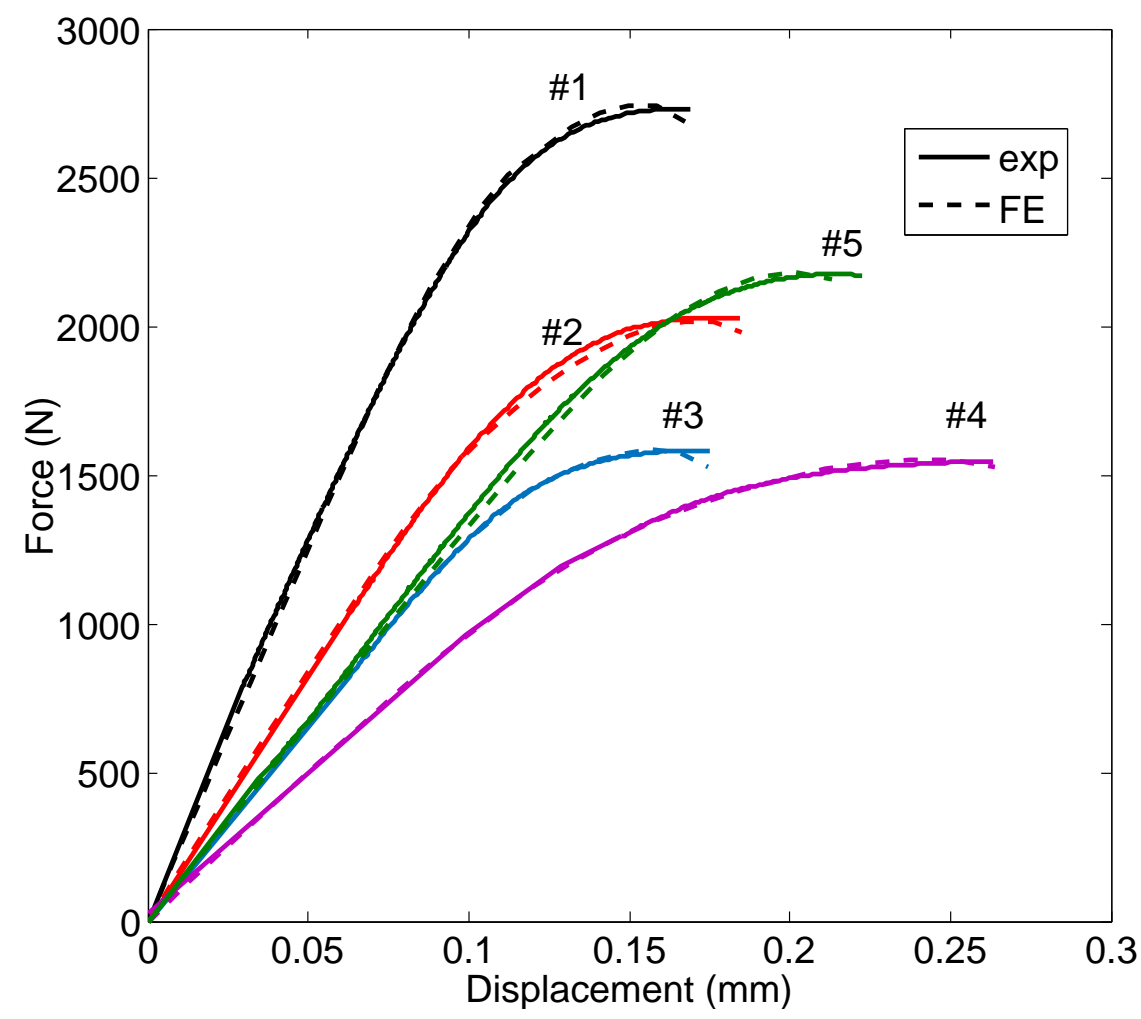

Figure 12: Compressive force-displacement response. Comparison between experiments and finite element models for each specimen. The yield strain and the strain at fracture were adjusted to match the FE curves to the experiments, in a back calculation procedure to estimate them.

uses a yield strain value of 0.0081 in a continuum damage approach which was obtained in [54] under a small deformation finite element approach. In the same work a yield strain value of 0.007 is obtained if the approach considers large deformations.

The failure model considered in this work is dependent on both $\varepsilon_{\mathrm{y}, \mathrm{c}}$ and $\varepsilon_{\mathrm{f}, \mathrm{c}}$. The ductility of the sample within this model has proved to be highly dependent on the difference between $\varepsilon_{\mathrm{y}, \mathrm{c}}$ and $\varepsilon_{\mathrm{f}, \mathrm{c}}$ values. As can be noted in 
Fig. 6, each of the specimens tested presents a different ductile behavior so, as reported in Table 5, different fracture values were set in order to reproduce the experimental response. The range of values obtained in this study are of the order of the proposed by Wolfram et al. [46] for unconfined axial compression. 


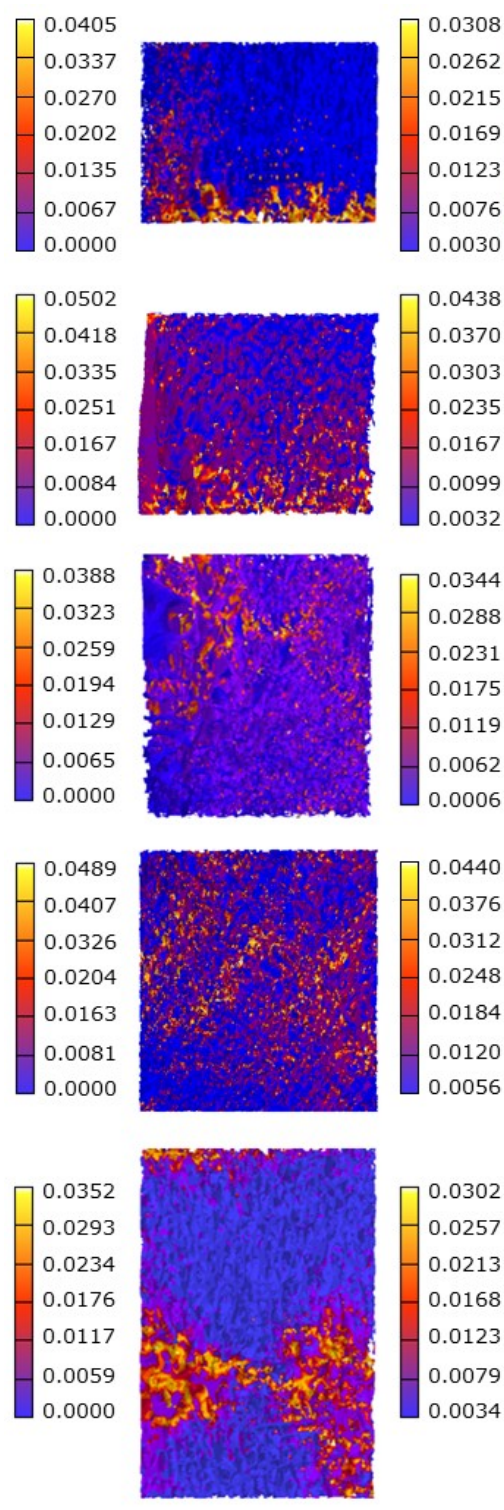

a)
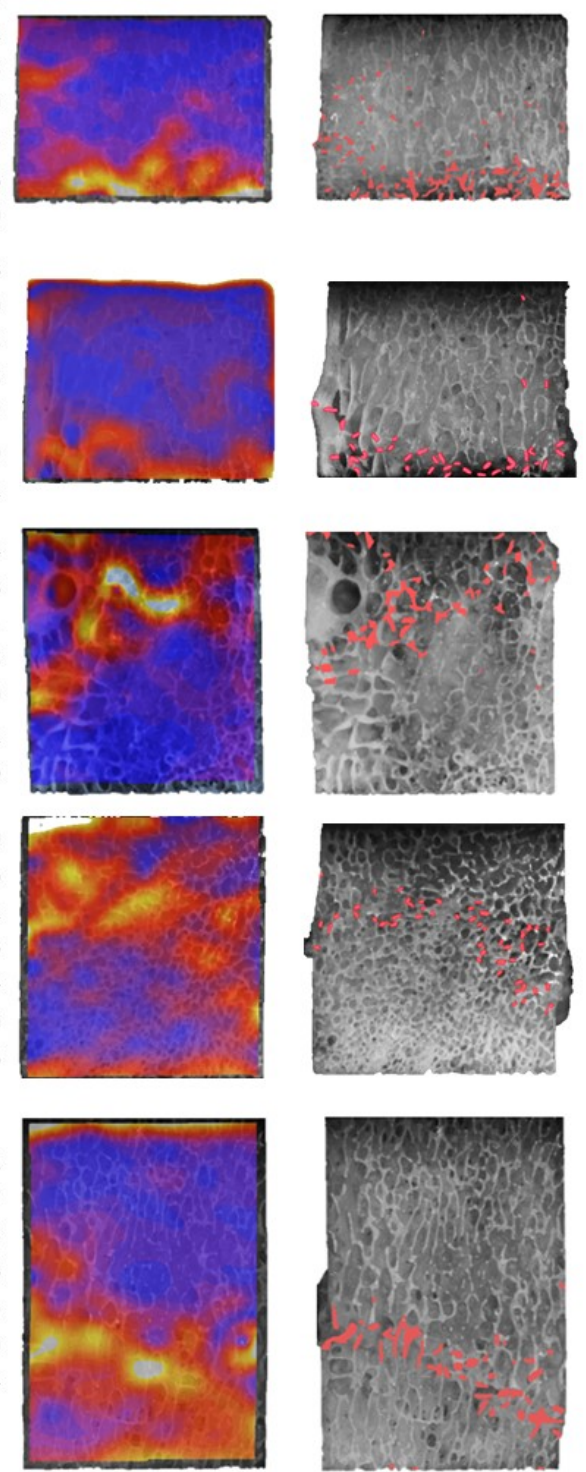

b)

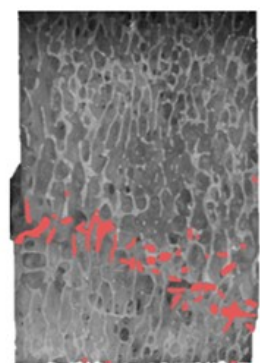

c)

Figure 13: Predicted fracture pattern for the five specimens simulated by means of a) micro-FE models, b) DIC and c) experimental fracture under compression testing, where regions highlighted in red have been identified by visual inspection. The field variable is the equivalent strain $\left(\varepsilon_{\mathrm{eq}}\right)$. 
Fig. 13 shows a comparison between the two methods studied in this work for fracture estimation. Both micro-FE and DIC represent the equivalent strain field at fracture. In the five cases studied, the maximum predicted $\varepsilon_{\text {eq }}$ at fracture is slightly higher using FE than through DIC. This finding is coherent as peak FE strains are located in single trabeculae, whereas in DIC the area of fracture is wider and thus the strain values are averaged (less local). The differences on peak strain range from 10 to $24 \%$ depending on the specimen, Fig. 13. It can be observed that a fairly good correlation between simulations, DIC and experiments is achieved. However, a more precise estimation of the fracture is obtained with micro-FE as it is capable of predicting isolated failures at the microscale (note the isolated trabecular failure in Specimen \#1 (Fig. 11, middle, a), which are observed experimentally in the middle region of the lattice but are not clearly detected by DIC). This phenomenon can be explained because the DIC technique performs a homogenization on the whole specimen, which implies a 3D to 2D conversion and an interpolation at a lower resolution.

Nevertheless, DIC offers a qualitative fracture pattern characterization reducing computation time compared to the high cost of the micro-FE simulations. DIC may be used as a simple tool for experimental validation of numerical models which has not been previously applied in the literature.

\section{Limitations of the study}

We acknowledge some limitations of the study. First, our analysis deals with 13 cancellous specimens, extracted from different vertebrae but from only two animals. This leads to a specific range of non-osteoporotic mi- 
crostructure with little variation among samples. Besides, three of the specimens suffered from border artifacts which caused crushing at the specimenplaten interface, so we excluded them from the study.

On the other hand, segmentation is a key aspect for finite element models based on high resolution images, because it conditions morphometry and mechanical properties derived from them. We followed a manual thresholding method, based on visual inspection, so slight variations on the threshold selection could be expected by the action of different technicians. Other approaches based on volume fraction or mineral content measurement may reduce the uncertainties about segmentation threshold definition.

Moreover, we explored relationships between morphometry and mechanics, which are limited to the size of the study dataset and we did not perform adjustment for multiple comparison because of the difficulty for ensuring a generalization of the universal null hypothesis,-which contradicts empirical science and because of the nature of the exploratory study performed $[55,56]$. Se, the significant associations obtained between microstructure and mechanics need to be confirmed in ether, works.

On the other hand, our application of DIC to describe strain inhomogeneities and characterize cancellous bone fracture pattern was purely 2D and cancellous bone compression fracture is a 3D ent, so the results are limited to the visible surface where images were taken. Furthermore, DIC performs a certain homogenization regarding strain inhomogeneities detection, and not only the outer surface affects to the strain computation, but also subsequent surfaces, as already stated by others [22]. Nevertheless, this was not problematic in fracture pattern comparison because of the foamed nature 
of the samples, which permitted to observe fracture up to a certain depth. Anyway, a 3D application of DIC is also referred to the surfaces viewed by the cameras, so internal fractures can not be characterized by DIC technique. For hose purpeses, digital volume correlation (DVC) should be used.

Regarding numerical modeling, bone is known to have a certain degree of viscoelastic, heterogeneous and anisotropic behavior, while we have approximated it as an elastic, homogeneous and isotropic material. The effect of more realistic properties on the estimation of failure parameters would be addressed in future works.

\section{Conclusions}

In this work, quasi-static compression fracture is carried out on 13 cancellous bone specimens. Two methods were used to detect the onset of failure and its propagation: DIC and micro-FE modeling. As part of the DIC application to characterize fracture patterns, three different strain-based variables were compared $\left(\varepsilon_{1}, \tau_{12}\right.$ and $\left.\varepsilon_{\text {eq }}\right)$. Fracture patterns were best characterized by means of $\varepsilon_{\text {eq }}$, which takes into account both normal and shear strains contributions. Regarding failure properties estimation through micro-FE simulations, a yield strain of 0.0068 proved to be suitable to define damage initiation over all samples tested. On the other hand, compressive strain at fracture differed between specimens. However, the calculated values are in the range of those published in [46]. The fracture pattern predicted by DIC and micro-FE methods was close to the experimental one but more accuracy was obtained using micro-FE modeling due to the lower number of image correlation points of the DIC technique. The non-speckle approach of DIC 
provides reasonable results for experimental validation of fracture models. Quantitatively, it appears to underestimate peak strain with respect to FE models with differences ranging from 10 to $24 \%$.

The importance of a correct segmentation has also been highlighted, showing that a variation of $\pm 15 \%$ in the segmentation threshold can lead to variations up to $\pm 42 \%$ in the apparent Young's modulus of the specimen.

Regarding future works a more complex failure mode criterion would be of great clinical and research interest, aiming at cancellous bone lattice microstructure. This way, buckling, traction, shearing and combined failure modes could be distinguished and more information about the way in which cancellous bone fractures at the microscale level would be available.

\section{Acknowledgments}

This work was supported by the Spanish Ministerio de Ciencia, Innovación y Universidades [grant numbers DPI2013-46641-R and DPI2017-89197-

C2-2-Rfand the Generalitat Valenciana fProgramme PROMETEO 2016/007t. The micro-CT acquisitions were performed at CENIEH facilities with the collaboration of CENIEH staff. The authors also gratefully acknowledge the collaboration of Ms. Lucía Gómez. 


\section{References}

[1] Gold DT. The nonskeletal consequences of osteoporotic fractures: Psychologic and social outcomes. Rheum Dis Clin N Am 2001;27(1):255-62. https://doi.org/10.1016/S0889-857X(05)70197-6

[2] Keaveny TM, Morgan EF, Niebur GL, Yeh OC. Biomechanics of trabecular bone. Annu Rev Biomed Eng 2001;3:307-33. https://doi.org/10.1146/annurev.bioeng.3.1.307

[3] Rho JY, Kuhn-Spearing L, Zioupos P. Mechanical properties and the hierarchical structure of bone. Med Eng and Phys 1998;20:92-102. https://doi.org/10.1016/S1350-4533(98)00007-1

[4] Currey JD. The structure and mechanics of bone. J Mater Sci 2012;47:41-54. https://doi.org/10.1007/s10853-011-5914-9

[5] Cowin SC. Bone mechanics handbook. Boca Ratón, Florida:CRC Press;2001. ISBN 9780849391170 - CAT\# 9117

[6] Alberich Bayarri A. In vivo morphometric and mechanical caracterization of trabecular bone from high resolution magnetic resonance imaging. PhD Thesis. UPV, Valencia (2010). https://doi.org/10.4995/Thesis/10251/8981

[7] Gupta HS, Zioupos P. Fracture of bone tissue: The hows and the whys. Med Eng Phys 2008;30:1209-26. https://doi.org/10.1016/j.medengphy.2008.09.007 
[8] van Rietbergen B, Weinans H, Huiskes R, Odegaard A. A new method to determine trabecular bone elastic properties and loading using micromechanical finite-element models. J Biomech 1995;28(1):69-85. https://doi.org/10.1016/0021-9290(95)80008-5

[9] Hambli R. Micro-CT finite element model and experimental validation of trabecular bone damage and fracture. Bone 2013;56:363-74. https://doi.org/10.1016/j.bone.2013.06.028

[10] Nagaraja S, Couse TL, Guldberg RE. Trabecular bone microdamage and microstructural stresses under uniaxial compression. J Biomech 2005;28:707-16. https://doi.org/10.1016/j.jbiomech.2004.05.013

[11] Schwiedrzik J, Gross T, Bina M, Pretterklieber M, Zysset P, Pahr D. Experimental validation of a nonlinear $\mu \mathrm{FE}$ model based on cohesivefrictional plasticity for trabecular bone. Int J Numer Meth Biomed Engng 2015;32(4):e02739. https://doi.org/10.1002/cnm.2739

[12] O'Connor DT, Elkhodary KI, Fouad Y, Greene MS, Sabet FA, Qian J, Zhang Y, Liu WK, Jasiuk I. Modeling orthotropic elasticity, localized plasticity and fracture in trabecular bone. Comput Mech 2016;58:42339. https://doi.org/10.1007/s00466-016-1301-3

[13] García D, Zysset P, Charlebois M, Curnier A. A three-dimensional elastic plastic damage constitutive law for bone tissue. Biomech Model Mechanobiol 2009;8:149-65. https://doi.org/10.1007/s10237-008-0125-2

[14] Hambli R, Thurner PJ. Finite element prediction with experimental validation of damage distribution in single trabeculae during three- 
point bending tests. J Mech Behav Biomed Mater 2013;27:94-106. https://doi.org/10.1016/j.jmbbm.2013.07.005

[15] Hambli R. A quasi-brittle continuum damage finite element model of the human proximal femur based on element deletion. Med Biol Eng Comput 2013;51:219-31. https://doi.org/10.1007/s11517-012-0986-5

[16] Fan R, Gong H, Zhang X, Liu J, Zhengbin J, Zhu D. Modeling the mechanical consequences of aged-related trabetular bone loss by XFEM simulation. Comput Math Methods Med 2016;vol. 2016, Article ID 3495152, 12 pages. http://dx.doi.org/10.1155/2016/3495152

[17] Vellwock AE, Vergani L, Libonati F. A multiscale XFEM approach to investigate fracture behavior of bio-inspired composite materials. Comp Part B: Engineering 2018;141:258-64. https://doi.org/10.1016/j.compositesb.2017.12.062

[18] Hambli R. Multiscale prediction of crack density and crack length accumulation in trabecular bone based on neural networks and finite element simulation. Int J Numer Methods Biomed Eng 2011;27(4):461-75. https://doi.org/10.1002/cnm.1413

[19] Hambli R. Apparent damage accumulation in cancellous bone using neural networks. J Mech Behav Biomed Mater 2011;4(6):868-78. https://doi.org/10.1016/j.jmbbm.2011.03.002

[20] Lemaitre J. A continuous damage mechanics model for ductile fracture. J Eng Mater Technol 1985;107:83-9. https://doi.org/10.1115/1.3225775 
[21] Turner CH, Burr DB. Basic biomechanical measurements of bone: A tutorial. Bone 1993;14:595-608. https://doi.org/10.1016/87563282(93)90081-K

[22] Bay BK. Texture correlation: a method for the measurement of detailed strain distributions within trabecular bone. J Orthop Res 1995;13:25667. https://doi.org/10.1002/jor.1100130214

[23] Peters WH, Ranson WF. Digital imaging techniques in experimental stress analysis. Opt Eng 1982;21:427-31. https://doi.org/10.1117/12.7972925

[24] Sutton MA, Wolters WJ, Peters WH, Ranson WF, McNeil SR. Determination of displacement using an improved digital correlation method. Image Vis Comput 1983;1:133-39. https://doi.org/10.1016/02628856(83)90064-1

[25] Pan B, Qian K, Xie H, Asundi A. Two-dimensional digital image correlation for in-plane displacement and strain measurement: A review. Meas Sci Technol 2009;20(6):062001. https://doi.org/10.1088/0957$0233 / 20 / 6 / 062001$

[26] Khoo S, Karuppanan S, Tan C. A review of surface deformation and strain measurement using two-dimensional digital image correlation. Metrol Meas Syst 2016;3:461-80. https://doi.org/10.1515/mms-20160028

[27] Palanca M, Tozzi G, Cristofolini L. The use of digital image correla- 
tion in the biomechanical area: A review. Int Biomech 2016;3:1-21. https://doi.org/10.1080/23335432.2015.1117395

[28] Gustafson HM, Cripton PA, Ferguson SJ, Helgason B. Comparison of specimen-specific vertebral body finite element models with experimental digital image correlation measurements. J Mech Behav Biomed Mater 2017;50:43-54. https://doi.org/10.1016/j.jmbbm.2016.10.002

[29] Grassi L, Isaksson H. Extracting accurate strain measurements in bone mechanics: A critical review of current methods. J Mech Behav Biomed Mater 2015;50:43-54. https://doi.org/10.1016/j.jmbbm.2015.06.006

[30] Grassi L, Väänänen SP, Ristinmaa M, Jurvelin JS, Isaksson H. How accurately can subject-specific finite element models predict strains and strength of human femora? Investigation using full-field measurements. J Biomech 2017;65:801-7. https://doi.org/10.1016/j.jbiomech.2016.02.032

[31] Bayraktar HH, Morgan EF, Niebur GL, Morris GE, Wong EK, Keaveny TM. Comparison of the elastic and yield properties of human trabecular and cortical bone tissue. J Biomech 2004;37:27-35. doi:10.1016/S00219290(03)00257-4

[32] Carretta R, Stüssi E, Müller R, Lorenzetti S. Within subject heterogeneity in tissue-level post-yield mechanical and material properties in human trabecular bone. J Mech Behav Biomed 2013;24:64-73. http://dx.doi.org/10.1016/j.jmbbm.2013.04.014 
[33] Linde F, Sorensen HCF. The effect of different storage methods on the mechanical properties of trabecular bone. J Biomech 1993;26(10):124952. https://doi.org/10.1016/0021-9290(93)90072-M

[34] Linde F, Hvid I. Stiffness behaviour of trabecular bone specimens. J Biomech 1987;20(1):83-9. https://doi.org/10.1016/0021-9290(87)902703

[35] Keaveny TM, Borchers RE, Gibson LJ, Hayes W. Theoretical analysis of the experimental artifact in trabecular bone compressive modulus. J Biomech 1993;26(4-5):599-607. https://doi.org/10.1016/00219290(93)90021-6

[36] Keaveny TM, Guo XE, Wachtel EF, McMahon A, Hayes W. Trabecular bone exhibits fully linear elastic behavior and yields at low strains. J Biomech 1994;27(9):1127-36. https://doi.org/10.1016/00219290(94)90053-1

[37] Keaveny TM, Pinilla TP, Crawford RP. Kopperdahl DL, Lou A. Systematic and ramdom errors in compression testing of trabecular bone. J Orthop Res 1997;15:101-10. https://doi.org/10.1002/jor.1100150115

[38] Correlated Solutions. VIC-2D v6 Reference Manual 2016. http://www.correlatedsolutions.com/supportcontent/Vic-2D-v6Manual.pdf

[39] Whitehouse WJ. The quantitative morphology of anisotropic trabecular bone. J Microsc 1974;101(2):153-68. https://doi.org/10.1111/j.13652818.1974.tb03878.x 
[40] Kabel J, van Rietbergen B, Dalstra M, Odgaard A, Huiskes R. The role of an effective isotropic tissue modulus in the elastic properties of cancellous bone. J Biomech 1999;32:673-80. https://doi.org/10.1016/S00219290(99)00045-7

[41] Jirásek M. Damage and smeared crack models. In: Hofstetter G and Meschke G, editors. Numerical modeling of concrete cracking, CSIM courses and lectures, Wien:Springer; 2011;532:1-49. https://doi.org/10.1007/978-3-7091-0897-0

[42] Nalla RK, Kinney JH, Ritchie RO. Mechanistic fracture criteria for the failure of human cortical bone. Nat Mater 2003;2:164-68. https://doi.org/10.1038/nmat832

[43] Taylor D, Lee TC. A crack growth model for the simulation of fatigue in bone. Int J Fatigue 2003;2:387-95. https://doi.org/10.1016/S01421123(02)00165-2

[44] Burr DB, Stafford T. Validity of the bulk-staining technique to separate artifactual from in vivo bone microdamage. Clin Orthop Relat Res 1990;260:305-8. https://doi.org/10.1097/00003086-199011000-00047

[45] Keaveny TM, Haves WC. A 20-year perspective on the mechanical properties of trabecular bone. J Biomech Eng 1993;115(4B):534-42. https://doi.org/10.1115/1.2895536

[46] Wolfram U, Wilke HJ, Zysset PK. Damage accumulation in vertebral trabecular bone depends on loading mode and direction. J Biomech 2011;44(6):1194-9. https://doi.org/10.1016/j.jbiomech.2011.01.018 
[47] Kopperdahl DL, Keaveny TM. Yield strain behavior of trabecular bone. J Biomech 1998;31:601-8. https://doi.org/10.1016/S00219290(98)00057-8

[48] Ulrich D, van Rietbergen B, Laib A, Rüegsegger P. The ability of three-dimensional structural indices to reflect mechanical aspects of trabecular bone. Bone 1999;25(1):55-60. https://doi.org/10.1016/S87563282(99)00098-8

[49] Hara T, Tanck E, Homminga J, Huiskes R. The influence of microcomputed tomography threshold variations on the assessment of structural and mechanical trabecular bone properties. Bone 2002;31:107-9. https://doi.org/10.1016/S8756-3282(02)00782-2

[50] Parkinson IH, Badiei A, Fazzalari NL. Variation in segmentation of bone from micro-CT imaging: implications for quantitative morphometric analysis. Australas Phys Eng Sci Med 2008;31:160-4. https://doi.org/10.1007/BF03178592

[51] Wachtel EF, Keaveny TM. Dependence of trabecular damage on mechanical strain. J Orthop Res 1997;15:781-7. https://doi.org/10.1002/jor.1100150522

[52] Nazarian A, Meier D, Müller R, Snyder BD. Functional dependence of cancellous bone shear properties on trabecular microstructure evaluated using time-lapsed micro-computed tomographic imaging and torsion testing. J Orthop Res 2009;27:1667-74. https://doi.org/10.1002/jor.20931 
[53] Schwiedrzik J, Taylor A, Casari D, Wolfram U, Zysset P, Michlet J. Nanoscale deformation mechanisms and yield properties of hydrated bone extracellular matrix. Acta Biomater 2017;60:302-14. https://doi.org/10.1016/j.actbio.2017.07.030

[54] Bevill G, Eswaran SK, Gupta A, Papadopoulos P, Keaveny TM. Influence of bone volume fraction and architecture on computed largedeformation failure mechanisms in human trabecular bone. Bone 2006;39:1218-25. https://doi.org/10.1016/j.bone.2006.06.016

[55] Rothman KJ. No adjustments are needed for multiple comparisons. Epidemiology 1990;1:43-6. PMID: 2081237

[56] Althouse AD. Adjust for multiple comparisons? It's not that simple. Ann Thorac Surg 2016;101:1644-5. https://doi.org/10.1016/j.athoracsur.2015.11.024 